their neighbourhood leading to stagnation, concentration, and deposit of salts.

There is some resemblance beween these opacities and the arcus senilis; the arcus is more likely to occur in eyes which have had corneal ulceration, that is, where nutrition has been interfered with; the clcar space between the outer edge of the arcus and the scleral edge is analogous to the clear space between the concave edge of the cap and the end of the leash of vessels.

In one or two cases, round clear holes, like those found in the calcareous bands, have been seen; but no evidence of calcareous deposit, such as roughening of the surface, has been seen even where the mushroom has existed for seventy years.

\title{
AN UNUSUAL CASE OF IDIOSYNCRASY TO QUININE
}

\author{
BY
}

\section{Lieut.-Colonel Robert Henry Elliot, I.M.S. (Ret.)}

LONDON.

MR. A. G., a dispensing chemist, understanding that the writer was interested in quinine poisoning, consulted him as to the nature of certain unpleasant symptoms, which he experienced when he took low doses of ammoniated quinine or of any other form of the drug for influenzal colds. He stated that within a quarter of an hour of taking the drug, he suffered from headache, deafness, a difficulty in seeing clearly, and a contraction of his field of vision. At the same time, he found a difficulty in reading, the letters appearing doubled. He consented to take a low dose for the purpose of observation. That actually taken was 2 grains of powdered sulphate of quinine in a cachet. Being a very busy man, the time he could give was limited.

On examination beforehand, it was found that the edges of his disc were slightly blurred and surrounded by faint haloes; the appearances suggested that he might at some time have had a very mild optic neuritis; the colour of the discs was normal. He stated that some years previously, he had had a severe attack of influenza, and had noticed that his sight had been worse ever since. The R.E.V. $=6 / 6$ nearly, not improved by spheres; L.E.V. $=6 / 6$ slowly but correctly; the diameter of each pupil $=3.5 \mathrm{~mm}$. ; he read No. 1 type easily with his own glass at $41 \mathrm{~cm}$.

Twenty minutes after swallowing the quinine, he had a headache, and was deaf and rather slow in manner. R.E.V.=6/12 partly; L.E.V. $=6 / 6$ partly; the optic discs were decidedly paler than before, and the arteries were slightly but distinctly lessened in 
calibre. He read the same type as before at $41 \mathrm{~cm}$., but had much more difficulty in so doing. Examined three quarters of an hour after the original dose, the pallor of the discs was accentuated, and the arteries were smaller, one of the latter (supero-temporal branch, R.E.), which showed a sharp kink under ordinary circumstances, now appeared to have its lumen obliterated at this point. The pupils were each $4.5 \mathrm{~mm}$. in diameter as against $3.5 \mathrm{~mm}$. before the induction of cinchonism. They reacted to light and slightly to accommodation.

The most remarkable changes, however, were in the fields of
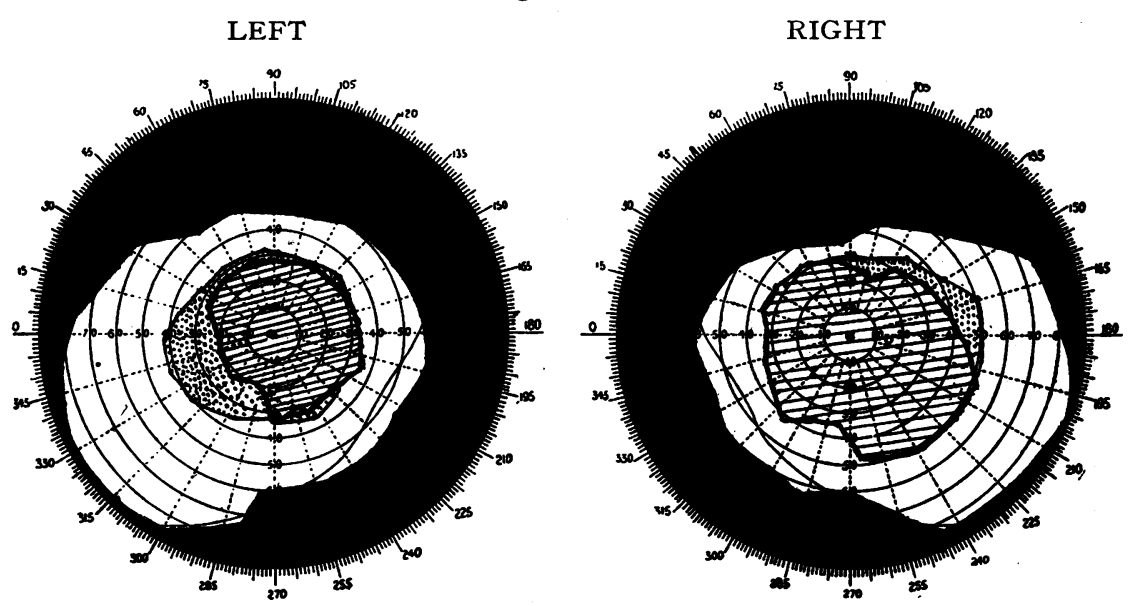

The white areas show the normal fields, as taken before quinine was administered. The shaded areas show the fields taken half an hour after the dose of 2 grains of powdered sulphate of quinine. The dotted areas show the portions added to each field 15 minutes after a cup of strong coffee had been taken and one hour after the original dose. At this time he stated that he felt his fields were improving. The examination was made with a $1 \mathrm{~mm}$. moderately bright spot, with a self-lit electric perimeter, in a dull light in a dark room. Under these conditions, the normal fields should have been a little over the full.

vision, as shown in the accompanying charts. The outside white limits represent the fields before the experiment commenced. The shaded areas show the portion of field left when taken half-an-hour after the quinine was administered. A self-lit electric perimeter was used, the object employed being a $1 \mathrm{~mm}$. spot of moderately bright light, which in a normal eye should have given a full normal field. It will be observed that it did not do so, even before the drug was given, thus suggesting that the optic nerve was not wholly normal to start with. A control experiment was made on a patient who had occasion to take 10 grains of hydrochloride of quinine; his fields, etc., remained quite unaltered.

The patient had stated that a cup of coffee relieved his symptoms and speedily restored the field to normal. $\mathrm{He}$ was accordingly 
given a cup of strong coffee 45 minutes after the quinine dose. His fields were taken a quarter of an hour later, at which time he stated that he was beginning to feel better; the resulting improvement in each field has been shown by dotting the area gained. The patient's time being limited, the experiment had to be brought to an end. The colour vision remained normal throughout. It was not possible to test his light sense in the time available.

Remarks.-The main interest of the case lies in the fact that the dose given is the lowest yet recorded as having provoked quinine amblyopia, with a record supported by a careful examination of the patient. The extent of the reduction of the fields is remarkable, but the patient maintained that it was much less than he had often experienced. He attributed this to the good state of health he was in at the time. Possibly the fact that he took the quinine in powder instead of, as he had previously often done, in a solution of the ammoniated drug, furnishes a more reasonable explanation. The writer was naturally handicapped by his anxiety not to overdo the effect produced.

Caffeine has been recommended in the treatment of quinine amblyopia. A doubt as to the advisability of using this drug as a remedy might arise from Schwabe's case of a woman of 33, who had suffered for years from quinine amblyopia, and whose fields were always rapidly contracted by the ingestion of strong tea or coffee. That case is a very difficult one to understand, and the observations now published appear to indicate that caffeine has justly earned a reputation in the treatment of quinine amblyopia.

The question arises as to whether the original trouble with his vision may not have been due to the quinine then taken, rather than to the influenza. It is quite clear from the records of other cases that a previous decided attack of quinine amblyopia may render a patient unduly sensitive to the action of the drug ever afterwards.

The large doses in which some experts in tropical disease are advocating nowadays that quinine should be administered, raise a situation which demands that all cases of quinine amblyopia should be published. It seems doubtful if they have realised the danger that threatens the patient from the ophthalmic side of the question.

\section{THYROID THERAPY IN OPHTHALMIC PRACTICE BY}

$$
\underset{\text { Pondon }}{\text { Percy DuN, }}
$$

Two years ago I contributed to the Lancet a paper entitled "Some Aspects of the Ciliary Body in Health and Disease,"* detailing

* The Lancet, 1916, Vol. 1. 